\title{
Histopathologic Study of Orbito-ocular Lesions
}

\author{
Laxman Banstola $^{1}$, Eliya Shrestha ${ }^{2}$, Swasti Sharma ${ }^{3}$ \\ ${ }^{1}$ Consultant Pathologist, Pokhara Academy of Health Sciences \\ ${ }^{2}$ Consultant Ophthalmologist, Himalayan Eye Hospital, Gharipatan, Pokhara \\ ${ }^{3}$ Consultant ENT Surgeon, Pokhara Academy of Health Sciences
}

\section{Correspondance:}

Dr Laxman Banstola

Pokhara Academy of Health Sciences,

Pokhara

Email:1banstola@hotmail.com

Article received: Dec 172019

Article accepted: Feb 32020

\section{ABSTRACT}

Background: Various neoplastic and non-neoplastic diseases affect the eye and orbit. Different tissues of ocular area contribute to lesions that varies from inflammation to different types of neoplastic conditions. Histopathology is the key to diagnosis for most neoplastic and non-neoplastic swellings. Histopathological studies have the indirect role to ongoing patient care.

Materials and Methods: It was a retrospective study of ocular biopsies done in Himalayan Eye Hospital Gharipatan, Pokhara. These biopsy specimens were submitted during the period of one year $(2018 / 12 / 1$ to $2019 / 12 / 1)$.

Results: The total number of biopsies we analyzed for ocular lesions were 102. Maximum number of patients were from the second decade. Out of 102 cases, 7(6.86\%) were neoplastic and 95(96.07\%) were non neoplastic cases. Two cases of SCC were diagnosed out of 102 specimens, while one case each of non-Hodgkin's lymphoma and meibomian gland carcinoma were detected.

Conclusion:Epidermal cyst and nevus were the most common non-neoplastic lesions in this study. SCC and non-Hodgkin's lymphoma were the commonest malignant lesions in the present study.

Keywords: Histopathology, Squamous cell carcinoma, Nevus, non Hodgkin'slomphoma.

\section{INTRODUCTION}

The eyes are unique sensory organs. Diseases of the eyes, as with other organs,need to be studied both clinically and pathologically ${ }^{1}$. Orbital and ocular mass or tumours mostly require surgical treatment. Hence, a correct preoperative provisional diagnosis, derived from clinical examination and different investigations is important. Following surgical excision of any mass, histopathological examination of the operated specimen plays a major role in confirmation of the diagnosis, further treatment and patient management ${ }^{2}$.

Histopathology is the key to diagnosis for most neoplastic and non-neoplastic swellings ${ }^{3}$.It helps determining the malignant potential of the lesion and also reveals its exact nature and structure. Different tissues of ocular area contribute to lesions that varies from inflammation to different types of 
Original Article

neoplastic conditions. In comparison to other parts of body, ocular malignancy is relatively rare. It requires immediate diagnosis and management. If ignored, it can result into debility and loss of vision.

Histopathological studies have the indirect role to ongoing patient care. Ophthalmic surgeon needs to correlate histopathological information with patient history and other clinical data.

The objective of this study was to analyze the histopathological diagnosis of orbito-ocular lesions and to know the pattern of prevalence of ophthalmic lesions in tertiary care hospital in Pokhara, Nepal by retrieving the clinic based data of the patients.

\section{MATERIALS AND METHODS}

It was a retrospective study of ocular biopsies done in Himalayan Eye Hospital Gharipatan,Pokhara and sent topathology laboratory for histopathologic examinations. The samples were well labelled including details of clinical diagnosis and sites of biopsies. These biopsy specimens were submitted during the period of one year (2018/12/1 to 2019/12/1).

\section{RESULTS}

The total number of biopsies we analyzed for ocular lesions were 102.Among the 102 cases 53 were male and 49 were female patients with highest number of cases in the age group of 11-20 years. Maximum number of patients were from the second decade (Table 1).There were 63 biopsies $(61.78 \%)$ from eye lid, 26(23.52\%) from conjunctiva,14(13.72) from orbit and $1(0.98 \%)$ from canthus (table 2$)$.

Table 3 shows the diagnosis of study population. In this study, epidermal cyst (Figure 1) and nevus(Figure 2) contributed highest number of cases among the non-neoplastic ocular lesions. Invasive squamous cell carcinoma(SCC) was the most common malignant ocular lesion.

Out of 102 cases, 7(6.86\%) were neoplastic and 95(96.07\%) were non neoplastic cases. Two cases of SCC were diagnosed out of 102 specimens, while one case each of non-Hodgkin's lymphoma (figure 3)and meibomian gland carcinoma were detected (figure 4).Two cases of conjunctival
Medical Journal of Pokhara Academy of Health Sciences Vol. 3 Issue 1 intraepithelial neoplasia and one case of skin adnexal tumor contributed as benign neoplastic lesions. Epidermal cyst and nevus were the most common non-malignant lesion respectively followed by conjunctival inclusion cyst.

Table 1: Age distribution

\begin{tabular}{|l|l|l|}
\hline Age(Years) & No of patients & Percentage \\
\hline $0-10$ & 9 & 8.8 \\
\hline $11-20$ & 26 & 25.4 \\
\hline $21-30$ & 15 & 14.7 \\
\hline $31-40$ & 12 & 11.7 \\
\hline $41-50$ & 15 & 14.7 \\
\hline $51-60$ & 12 & 11.7 \\
\hline $61-70$ & 7 & 6.8 \\
\hline $71-80$ & 6 & 5.8 \\
\hline Total & 102 & 100 \\
\hline
\end{tabular}

Table2: Sites of lesions

\begin{tabular}{|l|l|l|}
\hline Site & No of patients & Percentage \\
\hline Eye lid & 63 & 61.76 \\
\hline Conjunctiva & 24 & 23.52 \\
\hline Orbit & 14 & 13.72 \\
\hline Canthus & 1 & 0.98 \\
\hline Total & 102 & 100 \\
\hline
\end{tabular}

Table 3: Diagnosis of orbito-ocular lesions

\begin{tabular}{|l|l|l|}
\hline Diagnosis & $\begin{array}{l}\text { No of } \\
\text { patients }\end{array}$ & $\begin{array}{l}\text { Perce- } \\
\text { ntage }\end{array}$ \\
\hline Epidermal cyst & 20 & 19.60 \\
\hline $\begin{array}{l}\text { Benign skin tumor with eccrine } \\
\text { differentiation }\end{array}$ & 1 & 0.98 \\
\hline $\begin{array}{l}\text { Conjunctival intraepithelial } \\
\text { neoplasia }\end{array}$ & 2 & 1.96 \\
\hline Chronic inflammatory lesion & 5 & 4.90 \\
\hline Pyogenic granuloma & 6 & 5.88 \\
\hline Verruca vulgaris & 13 & 12.74 \\
\hline $\begin{array}{l}\text { Invasive squamous cell } \\
\text { carcinoma }\end{array}$ & 2 & 1.96 \\
\hline Pterygium & 3 & 2.94 \\
\hline Pingecula & 1 & 0.98 \\
\hline Compound nevus & 17 & 16.66 \\
\hline Intradermal nevus & 3 & 2.94 \\
\hline Nevus sebaceous Jadassohn & 1 & 0.98 \\
\hline
\end{tabular}




\begin{tabular}{|l|l|l|}
\hline Meibomian carcinoma & 1 & 0.98 \\
\hline Conjunctival inclusion cyst & 10 & 9.80 \\
\hline Keratinous cyst & 3 & 2.94 \\
\hline Benign cystic lesion & 1 & 0.98 \\
\hline Chalazion cyst & 1 & 0.98 \\
\hline Squamous cell papilloma & 11 & 10.7 \\
\hline Non Hodgkin's lymphoma & 1 & 0.98 \\
\hline Total & 102 & 100 \\
\hline
\end{tabular}
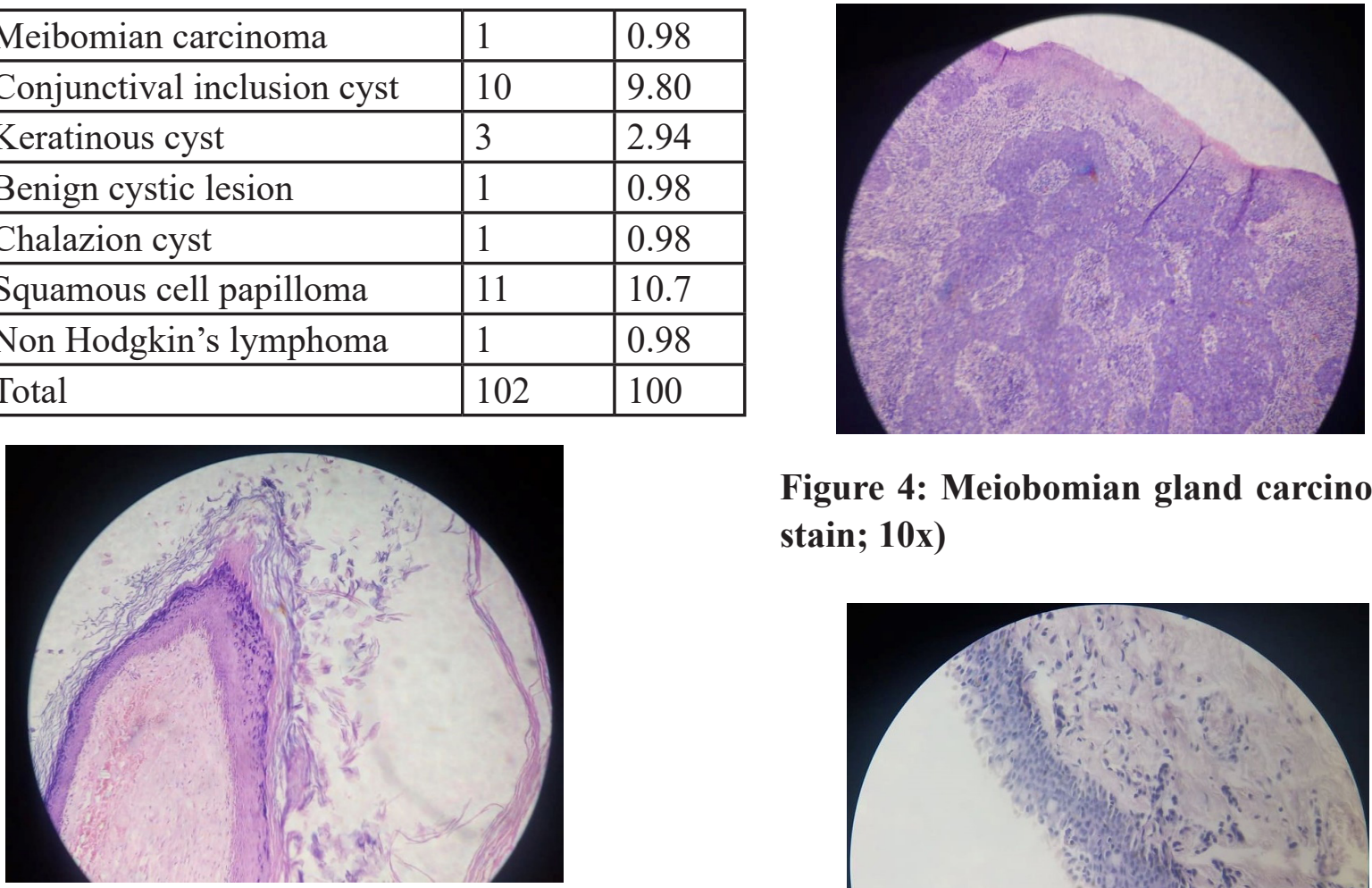

Figure 1: Epidermal cyst(H \& E stain; 10x)

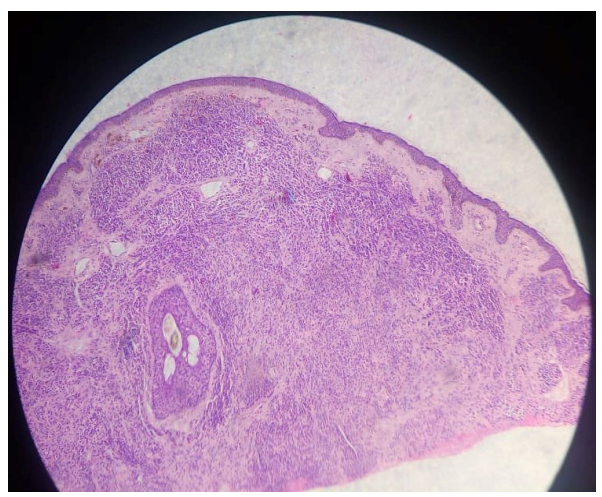

Figure 4: Meiobomian gland carcinoma(H \& E stain; 10x)

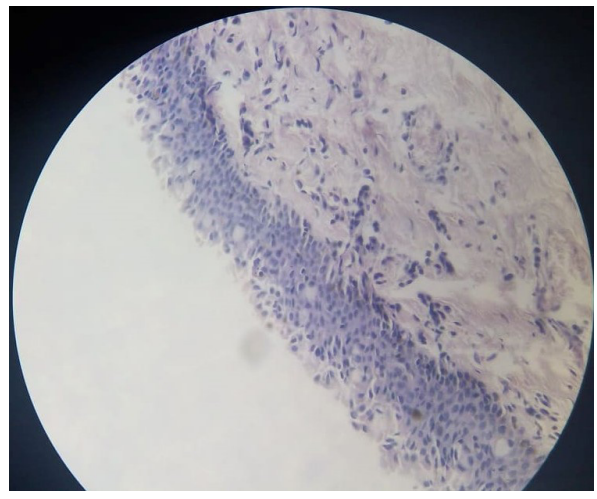

Figure 5: Conjunctival intraepithelial neoplasia(H \& E stain; 10x)

\section{DISCUSSION}

In the present study, neoplastic lesions were $6.86 \%$ while non neoplastic lesions were $96.7 \%$. Out of 102 cases, 7 were neoplastic and 95 were non neoplastic cases. Similar study conducted by Yashita Gupta et al showed result that non-neoplastic, benign and malignant lesions were $61.1 \%, 7.8 \%$ and $31.1 \%$ respectively ${ }^{1}$.

In the presentstudy, it was found that orbito-ocular lesions were highest in 11-20years (26\%) of age group. This may be due to frequent eye medical camp in schools and awareness programs in this region. However, in study conducted by Benedicta AghogoAkpe, majority of the cases were reported in 0-9years age group ${ }^{4}$.

Figure 3: Non-Hodgkin's lymphoma(H \& E stain; 10x)

In gender wisecomparison, there was not much 
Original Article

difference as $51.96 \%$ of patients were males and $48.03 \%$ were females.

In the present study, both nevus(including compound and intradermal) and epidermal cyst contributed highest number among non-neoplastic orbito-ocular lesions. There were 17 compound nevus( $16.66 \%)$ and 3 intradermal nevus(2.94\%). Similarly, there were 20 cases of epidermal cyst. In the similar study done by GarimaMurlidharAnandani et al. amongst the benign eyelid lesions, prevalence of nevus $(12.17 \%)$ was the highest followed by epidermal cyst $(11.30 \%)^{5}$.

Present study showed10 cases of conjunctival inclusion cyst. Shreya Thatte et al found various types of conjunctival cysts in their study ${ }^{6}$. They observed primary inclusion cyst in 12 cases $(30 \%)$, secondary inclusion cyst in (15\%), pterygium with cysts in $15(37.5 \%)$, parasitic cyst in4 (10\%), lymphatic cyst in $2(5 \%)$, and orbital cyst with rudimentary eye inone case $(2.5 \%)$.

In the present study there were 13 cases of verruca vulgaris(wart).In the study done by Yaser $\mathrm{H}$ et all there were $15.3 \%$ of verruca vulgaris cases among eye lid benign tumors?

The present study showed 11 cases of squamous cell papilloma(10.7\%). In a study done by SwathiKaliki et al among 73 patients with conjunctival papilloma, there were 10 children and adolescents ( $\leq 20$ years) and 63 adults $(>20 \text { years })^{8}$. In the study done by Zhonghuayankezazhi out of 5 leading causes of benign lid tumors,papillomas (658 cases, 27.9\%) was most common and rest were pigmented nevi (578 cases, $24.4 \%$ ), cysts (427 cases, $18.1 \%$ ), angiomas (222 cases, 9.4\% including 10 lymphangiomas) and verrucae (212 cases, $9.0 \%)^{9}$.

In the present study, four cases of malignancy were found. Two cases were diagnosed histologically as squamous cell carcinoma,one as non-Hodgkin's
Medical Journal of Pokhara Academy of Health Sciences Vol. 3 Issue 1 lymphoma and one as meibomian gland carcinoma. In the study done by Chinda $\mathrm{D}$ et aleighteen of the patients had retinoblastoma, eleven had squamous cell carcinoma, two had Kaposi' sarcoma, and one case was that of nasopharyngeal carcinoma. There were 2 patients with pre-malignant conditions and 10 patients with benign lesions ${ }^{10}$.

In present study, common ophthalmic malignancies like retinoblastoma, malignant melanoma, basal cell carcinomaetcwere not detected probably because the hospital lacks oncology department and so most of the suspected cases are referred to such centers where oncology service is available.

It is not an easy task to diagnose orbital lesions because most are not easily accessible and a firm clinical diagnosis requires a detailed history, clinical examination and investigations. Because it needs the high expense and adequate facilities for imaging techniques, low clinic-pathological correlation may be observed for orbital lesions in such poorly equipped centers.

\section{CONCLUSION}

Epidermal cyst and nevus were the most common non-neoplastic lesions in this study. SCC and non Hodgkin's lymphoma were the commonest malignant lesions in the present study. In order to come to a definitive diagnosis, histopathological examination of excised or incised orbital or ocular lesions is mandatory. However, clinical judgment does play a very important role in diagnosing the cases and treating them. The limitation of the study is that the diagnosis is based purely on morphological study. It would have been better if immunohistochemical test was available. Also, the study lacked the samples from visual pathway,retina and other important parts of eye. 


\section{REFERENCES}

1. Gupta Y, Gahine R, Hussain N, Memon MJ. Clinico-pathological spectrum of opthalmic lesion: An experience in tertiary care hospital of centreindia. J ClinDiagn Res 2017 Jan; 11(1): 9-13.

2. Banstola P, Koirala S, Pokhrel G, Ghimire P, Adhikari RK. Clinico-histopathological study of orbital and ocular lesions; a multicenter study. JCMC 2013; 3(4): 40-44.

3. Shastry S. Spectrum of histopathological study of ocular lesions: one year study. JNTR Univ Health Sci2014 ;3:12-4.

4. Akpe BA, Omoti AE, IyaseleET. Histopathology of ocular tumor specimens in Benin City, Nigeria. J Ophthalmic Vis Res 2009 Oct; 4(4): 232-237.

5. Anandani GM, PariKhSB, Shah NR. Histopathological Study of Eyelid Lesions. National Journal of Laboratory Medicine. 2018 Jan, 7(1): 7-118.

6. Thatte S,Jain J, Kinger M, Palod S, Wadhva J, Vishnoi A. Clinical study of histologically proven conjunctival cysts. Saudi J Ophthalmol. 2015 Apr-Jun; 29(2): 109-115.

7. Al-Faky YH. Epidemiology of benign eyelid lesions in patients presenting to a teaching hospital. SaudiJournal of Ophthalmology2012 April-June; 26(2):211216.

8. KalikiS,Arepalli S,Shields CL. Conjunctival Papilloma Features and Outcomes Based on Age at Initial Examination.JAMA Ophthalmol. 2013;131(5):585-593.

9. ZhonghuayankezaZhi. Histopathological classification of 3,510 cases witheyelidtumor. Chinese Journal of Ophthalmology1996 Nov, 32(6):435-437.

10. Chinda D, Samalia MO, Abah ER, Garba F, Rafindadi AL, Adamu A. A clinicopathological study of orbito-ocular tumors at Ahmadu Bello University Teaching Hospital, Shika-Zaria, Nigeria: A 5-year review. Clin Cancer Investig J 2012;1:145-7. 